\title{
Influência e Causalidade entre o Mercado de Ações e o Mercado de Opções: Revisão de Literatura e Novos Resultados
}

\author{
Jefferson da Cunha \\ Newton C. A. da Costa Jr.
}

\section{RESUMO}

Este artigo apresenta uma síntese da literatura a respeito do efeito dia de vencimento e também novos resultados sobre o assunto. Este efeito está relacionado ao impacto que o vencimento no mercado de opções tem sobre o volume transacionado, preço e retorno das ações subjacentes no mercado a vista. Por meio da metodologia de estudo de evento e de testes de causalidade foi possível avaliar a influência do vencimento das opções na BOVESPA sobre ações negociadas a vista, com dados diários e semanais durante o período de 1998 a 2001. Além disso, foi realizado um comparativo entre a utilização de preços de fechamento e preços máximos para o estudo proposto. Os resultados obtidos evidenciaram que existe influência significativa do mercado de opções sobre o mercado a vista, contestando a eficiência do mercado e implicando a possibilidade de se obterem retornos extraordinários, pelo menos na época do vencimento das opções. Concluise ainda que existe causalidade bilateral dos retornos entre os mercados estudados, que não há evidência de que o volume de títulos negociado no mercado de opções cause o volume de títulos no mercado a vista, nem o contrário. E que quanto mais in-the-money for a série de opções analisada, mais importante se tornam os retornos calculados com as cotações máximas diárias nos dois mercados para efeitos do estudo de causalidade proposto.

Palavras-chave: efeito dia-de-vencimento; estudo de evento; causalidade de Granger.

\begin{abstract}
This paper provides a synthesis of the existing literature on the expiration-day effects and presents some new results on the subject. These effects are related to the impact of the expiration of options on the trading volume, price, and return of the underlying securities. Event study and Granger causality tests were used to evaluate the influence of the expiration of the options traded in BOVESPA on the underlying stocks with daily and weekly data, in the period of 1998 to 2001 . Also, the use of closing prices and maximum prices for the proposed study were compared. The results showed a significant influence of the options market on the market of the underlying asset during the expiration day, contrasting with market efficiency and implicating in the possibility of obtaining extraordinary returns at least at that time. It was also concluded that although bilateral causality of the returns existed between the markets, there was no evidence that nor the volume of titles negotiated in the option market caused the volume of titles negotiated in the market of the underlying asset nor the opposite, and that the more in-the-money was the series of options, more important became the returns calculated with the daily high prices in the two markets for effects of the proposed causality study.
\end{abstract}

Key words: expiration-day-effect; event study; Granger causality. 


\section{INTRODUÇÃO}

Opções de ações foram primeiramente negociadas em bolsa em 1973, na Chicago Board Options Exchange (CBOE). Desde então os mercados de opções cresceram significativamente e hoje se constatam volumes expressivos de opções sendo negociados em quase todas as bolsas do mundo.

Sua importância está ligada à necessidade do posicionamento de hedgers, especuladores e arbitradores, cada um com suas especificidades de risco e retorno. Tais volumes de negociação com opções acontecem por necessidade de alavancagem extra, trava de posições com resultados certos ou oportunidades de travar lucros sem riscos. Sendo dotado de grande flexibilidade, permite variada gama de estratégias operacionais, que dão aos agentes econômicos diversas alternativas de investimento, com diferentes perfis de risco e retorno e, conseqüentemente, tornando o mercado financeiro mais completo.

O prêmio, que é o preço pago pelo titular ao lançador para adquirir a opção, é formado pelos compradores e vendedores no pregão das bolsas e reflete as condições de oferta e demanda prevalecentes. Independentemente do modelo de precificação de opções utilizado para avaliar seu valor intrínseco, com o intuito de realizar comparações com seu valor de mercado para estabelecer estratégias de investimento, esse preço depende do preço do ativo-objeto, do preço de exercício, do tempo para exercício, da volatilidade, da taxa de juro livre de risco e dos dividendos esperados durante a vida da opção. Como instrumento derivativo, supõe-se que seu preço seja influenciado pelo preço do ativo-objeto, e não o contrário; entretanto, na época do vencimento do contrato de opções, jornais, revistas, agentes financeiros e analistas sugerem que os investidores fiquem ausentes dos mercados de opções e de ações, dada a influência que aquele exerce sobre esse: é o chamado efeito dia de vencimento, expiration-day effect.

A importância de se estudar o efeito dia de vencimento fora dos EUA reside em dois motivos. O primeiro seria que para um mercado financeiro com instrumentos derivativos funcionar de maneira eficiente, os preços dos ativos subjacentes, negociados nos dias de vencimento destes derivativos, deveriam refletir o valor justo destes ativos. Se isso não ocorre, é possível que esteja havendo manipulação de preços; estudos adicionais serão necessários para verificar se a formação de preços nos dias de vencimento é normal. Em segundo lugar, como a maioria dos testes sobre o efeito dia de vencimento foi realizada nos EUA, é possível que as anomalias lá detectadas sejam devido à própria 
microestrutura deste mercado, tais como regras de transparência, restrições à venda a descoberto, maneira de se calcular os preços de ajustes e leilões de fechamento etc. Se este for o caso, seria possível alterar essa microestrutura, a fim de se evitar os efeitos negativos nos preços que acontecem nesse mercado.

O objetivo do presente trabalho é o de apresentar uma revisão de literatura sobre o efeito do vencimento de contratos derivativos sobre seus ativos objetos e apresentar novos resultados em relação à existência ou não de influência do vencimento de opções de compra, negociadas na Bolsa de Valores de São Paulo, sobre os preços e retornos de suas ações objeto, negociadas a vista. Adicionalmente, procura-se avaliar se existe vinculação do nível de atividade entre estes mercados, seja no volume de títulos negociados ou no preço dos ativos, em que sentido isso ocorre e com que freqüência e magnitude.

Na próxima seção faz-se uma revisão da literatura nacional e internacional sobre o efeito dia de vencimento. Na terceira seção são apresentadas, sucintamente, algumas características do mercado de opções no Brasil. Na quarta parte do trabalho apresenta-se a metodologia, a amostra escolhida e os resultados obtidos pelo método de estudo de evento e pelos testes de causalidade, respectivamente. A última parte resume as principais conclusões do trabalho.

\section{ReVisão dA Literatura}

\section{Estudo de Evento}

Muitos estudos foram realizados com o objetivo de verificar se o mercado de opções e de outros derivativos influencia o preço dos ativos subjacentes negociados a vista, no dia e em torno do vencimento desses contratos. Apresenta-se aqui breve revisão desses trabalhos, sem a pretensão de esgotar essa análise ${ }^{(1)}$.

Brito e Sosin (1984) desenvolveram o primeiro estudo no Brasil referente ao efeito dia de vencimento. Como na época do estudo existia o mercado futuro de ações na Bolsa de Valores do Rio de Janeiro (BVRJ), o enfoque de Brito e Sosin foi verificar a existência de efeitos anormais sobre o processo de formação de preços no mercado à vista que poderiam ser causados pelo vencimento de contratos futuros destes mesmos ativos. Os resultados da pesquisa, baseados na metodologia de estudo de evento e com cotações diárias das 10 ações mais negociadas na BVRJ, durante todos os vencimentos ocorridos no período de 1979 a 1982, não indicaram nenhum efeito estatisticamente significativo dos vencimentos futuros sobre as ações negociadas a vista. 
Outro trabalho relevante no mercado brasileiro sobre o efeito dia de vencimento foi o de Sanvicente e Kerr (1989) que, por meio também da metodologia de estudo de evento, analisa o comportamento de 15 ações no mercado a vista da Bolsa de Valores de São Paulo (BOVESPA), durante as semanas em torno de várias datas de vencimento de opções de compra ao longo do ano de 1985. Os resultados encontrados mostraram que não existiu nenhum comportamento anômalo das ações negociadas a vista durante os períodos de vencimento do mercado de opções, ou seja, não foi constatado o chamando efeito dia de vencimento.

Sanvicente (1996), em trabalho encomendado pela Comissão de Valores Mobiliários, analisa alguns aspectos do funcionamento do mercado de opções da BOVESPA e sua interação com o mercado a vista desta bolsa. Uma das partes de seu trabalho aborda o efeito dia de vencimento. Usando as cotações de fechamento de ações e suas opções de compra, durante o período de 1991 a 1995, e utilizando tanto dados diários como semanais, conclui que não há evidência de comportamento anormal no mercado a vista nas datas de vencimento das opções. Em outra parte do trabalho, o autor utiliza o teste de Granger (1969) para verificar alguma relação de causalidade entre o número de negócios realizados no mercado de opções e de ações, a fim de detectar a existência de alguma assimetria informacional entre esses mercados. Para tanto, utiliza o número de negócios diário, em termos agregados, realizado simultaneamente pelos dois mercados ao longo do mesmo período anterior. Os resultados evidenciaram uma demora de pelo menos dois dias para que o fluxo de informações atingisse o mercado a vista, a partir do mercado de opções, constatando, assim, a ineficiência ou assimetria informacional no mercado como um todo.

Körbes e Costa Jr. (2001) também utilizando a metodologia de estudo de evento, analisam o comportamento das ações da Telebrás PN durante o período de janeiro de 1996 a fevereiro de 1999, com dados semanais, e eliminando os meses pares (onde ocorrem os vencimentos de opções na BOVESPA) para a estimação dos parâmetros do modelo de mercado. Analisaram o vencimento de opções como evento que poderia aumentar o número de negócios e do volume financeiro no mercado a vista, provocando comportamentos anômalos em relação ao modelo de apreçamento utilizado. Através do Ibovespa e do Nispe-200, que é um índice ponderado pelo valor de mercado e, portanto, mais coerente com a definição teórica de carteira de mercado, concluíram que, independentemente do índice, o vencimento dos contratos de opções sobre ações não tem influência significativa sobre os preços do mercado a vista, corroborando a hipótese de mercados eficientes.

Em nível internacional, o primeiro estudo sobre o efeito dia de vencimento foi realizado por Klemkosky (1978), nos EUA. Com a utilização da metodologia de 
estudo de evento, encontrou retornos extraordinários negativos nas ações negociadas a vista na Bolsa de Nova York (NYSE) na semana anterior ao vencimento das opções negociadas na CBOE, mas que tiveram seu preço parcialmente revertido na semana seguinte. Officer e Trennepohl (1981), com o uso de dados diários, encontraram retornos extraordinários negativos nas quintas e sextas feiras imediatamente anteriores ao vencimento das opções, retornos negativos (não significativos) na segunda-feira após o vencimento e um retorno extraordinário positivo na terça feira. Pope e Yadav (1992) encontraram resultados similares no Reino Unido. Chen e Wu (2001), em pesquisa semelhante na Bolsa de Hong Kong, mas utilizando derivative equity warrants, encontraram um efeito positivo nos preços a vista antes e no dia de vencimento e negativo após o vencimento, para as warrants negociadas in-the-money e um efeito negativo nos preços a vista antes do vencimento e nenhum efeito após o vencimento para aquelas out-of-the-money. Este comportamento, segundo os autores, é explicado pela pressão de compra dos lançadores do papel que nas vésperas do vencimento se encontram in-the-money, a fim de se manterem hegdeados e pela pressão de venda no caso das warrants out-of-the-money, porquanto, neste caso, os lançadores das opções gradualmente vão desfazendo-se de sua posição comprada no ativo objeto.

\section{Outras Abordagens}

A característica comum a todos os estudos anteriores é a de que usaram, para detectar a presença de comportamento anormal de preços, o método de estudo de evento, desenvolvido nos trabalhos seminais de Ball e Brown (1968) e Fama, Fisher, Jensen e Roll (1969). Com a disponibilidade de dados intradiários e com técnicas estatísticas mais robustas, outras abordagens têm sido usadas para estudar o relacionamento entre mercados derivativos e a vista.

No Brasil, Sanvicente e Monteiro (2002) estudaram o efeito dia do vencimento, a partir de um sistema de equações formado por funções inversas da oferta e da demanda das ações da Telemar PN, que relacionam o preço negociado (ofertado/ demandado) à quantidade negociada (ofertada/demandada). Os autores mostram que os coeficientes de inclinação dessas funções inversas foram significativamente diferentes de zero no dia estudado (14 de dezembro de 2001), mostrando que tanto a elasticidade-preço da demanda como da oferta das ações da Telemar PN foram finitas, rejeitando a hipótese nula de elasticidade infinita, ou seja, a de que os investidores no mercado de ações seriam simples tomadores de preço. As decisões de compra e venda não deveriam alterar os preços do mercado, porque uma das conseqüências da hipótese de mercado eficiente é a de que os preços das ações deveriam alterar-se apenas com a chegada ao mercado de informações novas e relevantes, refletindo seu novo valor intrínseco. 
Stoll e Whaley (1987) constataram que a volatilidade do mercado e o volume negociado se elevavam na última hora dos dias de vencimento simultâneo do índice S\&P500 futuro e dos contratos de opções sobre o índice S\&P100. Este momento, segundo os autores, era conhecido como triple witching hour, que acontecia quatro vezes por ano. Com a constatação teórica de Stoll e Whaley e de outros trabalhos, a Chicago Mercantile Exchange, a New York Stock Exchange e a New York Futures Exchange fizeram acordo para alterar a hora de vencimento de alguns desses contratos. Mudaram o vencimento para a hora de abertura das bolsas, em vez do fechamento. Este efeito de mudar a hora de vencimento do S\&P500 tornou-se rapidamente um tema popular para se fazer pesquisas, segundo Felixson (2002). Stoll e Whaley (1991) compararam os períodos antes e depois da mudança e constataram os mesmos efeitos que antes, só que em vez destes efeitos acontecerem ao final do pregão, eles aconteciam no início.

Anthony (1988), utilizando-se da metodologia de Granger (1969), analisou dados diários de volume de negócios de 25 ações nos anos de 1982 e 1983 no mercado norte-americano e constatou que o volume negociado no mercado de opções antecipava-se ao do mercado a vista em praticamente um dia de pregão.

Outras evidências empíricas de que o mercado de opções influencia e lidera o mercado de ações, no sentido de causar ou anteceder, foram apresentadas por Manaster e Rendleman (1982) e Bhattacharya (1987).

Este ponto de vista foi alterado por Stephan e Whaley (1990), que argumentaram que o mercado a vista influencia e lidera o mercado de opções, como deveria ser esperado, sendo as opções instrumentos derivativos de ações a vista.

Chan, Chung e Johnson (1993) interpretaram os resultados de Stephan e Whaley (1990) para concluir que nenhum mercado lidera ou influencia o outro e ambos os mercados reagem de maneira simultânea ao aparecimento de novas informações ou fatos relevantes.

Ostdiek, Fleming e Whaley (1993) mostraram que existem indícios de que o mercado de opções negocia volumes financeiros em torno de 5 minutos antes do mercado a vista, mesmo depois do controle de trades não freqüentes, como grandes volumes financeiros de grandes operadores.

Boyle, Byoun e Park (1999) mostraram que, se existe relação temporal particular entre o mercado de opções e o mercado a vista, isto implica que a volatilidade nos preços das opções pode estar enviesada, dependendo do nível real de volatilidade do mercado. Quanto maior o nível de volatilidade, mais para cima estará enviesada a volatilidade, se o mercado de opções lidera ou antecede o 
mercado a vista. Eles usaram dados intradiários das opções do índice S\&P500, mostrando que o mercado de opções influencia o mercado a vista. Os resultados apóiam a noção de que os índices a vista possuem um atraso, enquanto os preços observados das opções refletem rapidamente toda a informação disponível.

Outros trabalhos procuraram estudar a relação entre os mercados futuros e os mercados de ações à vista com relação à eficiência dos mercados e sua microestrutura, como Finnerty e Park (1987), Kawaller, Koch e Koch (1987) e Kleidon e Whaley (1992).

\section{Características do Mercado de Opções e a Vista no Brasil}

No Brasil, as principais bolsas que negociam derivativos são a Bolsa de Mercadorias e Futuros (BM\&F) e a Bolsa de Valores de São Paulo (BOVESPA). Sendo que nesta última, foco deste trabalho, são negociadas opções de compra e venda de ações e de índices, além do mercado a vista e a termo de ações. No Quadro 1, a seguir, são apresentados alguns números da BOVESPA referentes ao ano de 2002.

\section{Quadro 1: Os Segmentos de Mercado e os Volumes Negociados na Bolsa de Valores de São Paulo, em 2002}

\begin{tabular}{|l|c|}
\hline \multicolumn{1}{|c|}{ Segmento do mercado } & $\begin{array}{c}\text { Volume negociado em 2002 } \\
\text { (milhões de dólares) }\end{array}$ \\
\hline Mercado a vista & $41.296,9$ \\
\hline Opções & $3.009,9$ \\
\hline Contratos a termo & $1.802,2$ \\
\hline Contratos futuros e outros & $3.162,3$ \\
\hline Total & $49.271,3$ \\
\hline
\end{tabular}

Fonte: Sanvicente (2003, p.28).

Observa-se que o volume total negociado em 2002 foi de pouco mais de US\$ 49 bilhões; mais de $80 \%$ deste volume se refere ao mercado a vista e pouco mais de $6 \%$ ao mercado de opções. Nesta última modalidade, a liquidez está concentrada nas opções de compra de ações, representando mais de $90 \%$ do volume negociado.

No período analisado neste estudo, as opções de compra e de venda, da BOVESPA, venciam na terceira segunda-feira do mês de vencimento, que eram os meses pares. 
Na prática brasileira, existe a proteção contra o pagamento de dividendos durante a vida da opção, na forma de ajuste pelo preço de exercício, da mesma forma proposta por Black e Scholes (1973). O valor de uma opção de compra aumenta à medida que aumenta o preço da ação, o tempo para o vencimento, a volatilidade e a taxa de juro livre de risco. O valor de uma opção de compra diminui com o aumento do preço do exercício e dos dividendos esperados. De forma análoga, o valor de uma opção de venda aumenta conforme aumenta o preço de exercício, o tempo de vencimento, a volatilidade e os dividendos esperados e diminui com a elevação do preço da ação e da taxa livre de risco.

Como opções são instrumentos derivativos, supõe-se que devam reagir ou seguir os preços dos ativos-objetos de que foram originados. Como mostramos anteriormente, trabalhos empíricos concluíram, em algum tempo ou em algum grau, o oposto disso. Seria o mesmo que dizer que o rabo abana o cachorro.

Este trabalho se restringe apenas à utilização das opções de compra (calls) exclusivamente pela inexistência de liquidez nas opções de venda (puts).

\section{Análise Empírica: Coleta de Dados, Metodologia e Resultados}

\section{Influência do Vencimento do Mercado de Opções sobre o Mercado a Vista}

Sem a existência de eventos importantes, como o vencimento do mercado de opções ou do índice futuro do Ibovespa, por exemplo, o mercado a vista deveria apresentar somente variações normais no sentido do equilíbrio risco-retorno de algum modelo de apreçamento de ativos. No caso do modelo de apreçamento ser o CAPM tradicional de Sharpe, Lintner e Mossin, a taxa de retorno esperado de uma ação em determinado período de tempo deveria ser explicada pelo produto de seu coeficiente beta e o prêmio de risco do mercado, somando o resultado à taxa de rentabilidade dos títulos do governo federal.

Utiliza-se aqui, nesta primeira parte de análise da influência de um mercado sobre o outro, a metodologia conhecida por e estudo de evento, desenvolvida por Ball e Brown (1968) e Fama et al. (1969). Ela consiste em calcular o retorno extraordinário de um ativo no tempo, que nada mais é do que a diferença entre a taxa de retorno efetivamente observada para determinada ação e a taxa que teria sido normal para essa ação em função do comportamento que o índice de mercado teve nas datas consideradas. Determina-se o evento de interesse (neste 
caso o vencimento do mercado de opções) e em que datas ele acontece, fazendo com que os retornos sejam medidos em torno dessas datas.

Com o uso desta metodologia, o objetivo é determinar se os retornos extraordinários observados são estatisticamente significantes, evidenciando então que o vencimento do mercado de opções influencia o mercado a vista (ou as ações-objeto) em sua trajetória normal, e que o seu funcionamento nesses períodos não segue a hipótese de mercados eficientes e/ou o modelo de apreçamento utilizado não é o correto.

Selecionou-se como ações do mercado a vista Telemar PN, Petrobrás PN e Telesp PN no período de 21 de setembro de 1998 até dezembro de 2001. Körbes e Costa Jr. (2001) já haviam trabalhado com os Recibos de Telebrás (RCTB40) no período de janeiro de 1996 a fevereiro de 1999. A escolha deste período se justifica pela alteração do mercado de ações brasileiro com o desmembramento de todas as empresas do antigo Sistema Telebrás, quando as ações da Telemar passaram a liderar o volume financeiro e de negócios da Bovespa, mas em uma parcela bem inferior àquela que representavam os RCTB40 anteriormente. A partir desse período, os negócios na Bovespa deixaram de se concentrar em alguns poucos papéis para mais do que uma dezena deles e os negócios com opções aumentaram também nas séries dessas ações.

Os retornos diários foram calculados sobre os preços de fechamento nominais (sem aplicação de logaritmo natural em razão do período estudado e do objetivo proposto), ajustados para dividendos, subscrições ou bonificações por meio do banco de dados da Economática. A partir desses retornos, para estimar os retornos normais esperados, de forma a compará-los posteriormente com os retornos observados e quantificar os resíduos, utilizou-se o modelo de mercado descrito na equação (1), abaixo:

$R_{i t}=\alpha_{j}+\beta_{i} R_{m t}+\varepsilon_{i t}$

Onde $\mathrm{R}_{\mathrm{jt}}$ é a taxa de retorno da ação $\mathrm{j}$ no período $\mathrm{t} ; \mathrm{R}_{\mathrm{mt}}$ é a taxa de retorno do índice de mercado no período t; $\varepsilon_{\mathrm{jt}}$ é o retorno específico (resíduo) da ação j no período t; e $\alpha_{\mathrm{j}}$ e $\beta_{\mathrm{j}}$ são os parâmetros do modelo de mercado para a ação j, a serem estimados por análise de regressão.

Os parâmetros $\alpha_{\mathrm{j}}$ (intercepto da reta de regressão) e $\beta_{\mathrm{j}}$ (coeficiente angular) foram obtidos a partir dos retornos diários de todos os meses do período analisado, incluindo aí os meses pares, onde ocorrem os vencimentos dos contratos de opções. Foram excluídas, para análise dos retornos observados ao redor das datas de vencimento, a semana anterior e a semana da data do vencimento dos contratos de opções. 
Foram utilizados dois índices para calcular o retorno normal pelo modelo de mercado: o Ibovespa, que pondera os pesos da participação das ações pelo seu índice de negociabilidade e fortemente concentrado em poucos papéis, e o FGV100, que reflete o comportamento de uma carteira teórica formada por ações de 100 empresas privadas não financeiras, selecionadas segundo a dimensão, o desempenho econômico-financeiro e a liquidez de cada empresa. Os resultados do modelo de mercado, utilizando-se dados diários são apresentados na tabela abaixo.

\section{Tabela 1: Intercepto e Grau de Inclinação das Ações em Relação aos Índices de Mercado, com Retornos Diários (set./98 a dez./01)}

\begin{tabular}{llrrr} 
& & Intercepto & Inclinação & \multicolumn{1}{l}{$\mathbf{R}^{\mathbf{2}}$} \\
\hline \multirow{2}{*}{ Telemar } & Ibovespa & 0,00074 & 1,22752 & 0,65852 \\
\cline { 2 - 5 } & FGV-100 & $-0,00109$ & 1,69140 & 0,60675 \\
\hline \multirow{2}{*}{ Petrobrás } & Ibovespa & 0,00104 & 0,82899 & 0,53471 \\
\cline { 2 - 5 } & FGV-100 & 0,00011 & 1,01325 & 0,38766 \\
\hline \multirow{2}{*}{ Telesp } & Ibovespa & $-0,00049$ & 1,07735 & 0,62174 \\
\cline { 2 - 5 } & FGV-100 & $-0,00214$ & 1,50216 & 0,58658 \\
\hline
\end{tabular}

Numa primeira análise observa-se que o $\mathrm{R}^{2}$, que mede o grau de ajuste da equação de regressão, ou seja, que fornece a proporção ou porcentagem da variação total nos retornos das ações explicados pelos retornos dos índices, é maior para o Ibovespa, o que minimiza a importância do FGV-100 como proxy do mercado, pelo menos no período e para as ações analisadas. Logicamente isso se justifica, porque as ações em análise possuem maior percentual de participação no Ibovespa do que no FGV-100. Uma redução nos dados utilizados, com a exclusão dos meses pares, por exemplo, onde ocorrem os vencimentos dos contratos de opções não melhora significativamente os ajustamentos das equações.

Os retornos extraordinários no período de análise foram calculados por:

$\mathrm{RR}_{\mathrm{jt}}=\mathrm{R}_{\mathrm{jt}}-\left(\alpha_{\mathrm{j}}+\beta_{\mathrm{j}} \mathrm{R}_{\mathrm{mt}}\right)$

onde $R_{\mathrm{jt}}$ é o retorno extraordinário ou resíduo da ação j no período t; e $\mathrm{R}_{\mathrm{jt}}$ é o retorno observado da ação $\mathrm{j}$ no período $\mathrm{t}$.

No período analisado, ocorreram 20 exercícios de opções. A Tabela 2 apresenta estas datas, com retornos observados naquele pregão em relação ao pregão 
anterior, além dos retornos extraordinários para cada um dos índices utilizados, para as três ações avaliadas.

Tabela 2: Retornos Normais e Extraordinários Diários das Ações para cada um dos Índices de Mercado, nos Dias de Vencimento das Respectivas Opções, Usando o Modelo de Mercado (set./98 a dez./01)

\begin{tabular}{|c|c|c|c|c|c|c|c|c|c|}
\hline $\begin{array}{c}\text { Exercício } \\
\text { de Opções }\end{array}$ & $\mathbf{R}_{\text {TNLP4, } t}$ & $\begin{array}{l}\mathbf{R}_{\text {TNLP4,t }} \\
\text { Ibovespa }\end{array}$ & $\begin{array}{l}\text { RR }_{\text {TNLP4,t }} \\
\text { FGV100 }\end{array}$ & $\mathbf{R}_{\text {PETR4, }}$ & $\begin{array}{l}\text { RR }_{\text {PETR } 4, t} \\
\text { Ibovespa }\end{array}$ & $\mid \begin{array}{l}\text { RR }_{\text {PETR } 4, t} \\
\text { FGV100 }\end{array}$ & $\mathbf{R}_{\text {TLPP4, }}$ & $\begin{array}{l}\mathbf{R}_{\text {TLPP4,t }} \\
\text { Ibovespa }\end{array}$ & $\begin{array}{l}\mathbf{R R}_{\text {TLPP4, }} \\
\text { FGV100 }\end{array}$ \\
\hline $19 / 10$ & 0,040 & & & & & & 0,036 & & \\
\hline $21 / 12 / 98$ & 0,083 & 006 & 029 & 0,056 & & & 0,044 & & $-0,003$ \\
\hline $08 / 02 / 99$ & 0,080 & 0,023 & 0,056 & 0,064 & 0,025 & 0,049 & 0,057 & 0,008 & 0,037 \\
\hline $19 / 04 / 99$ & $-0,015$ & & $-0,004$ & $-0,017$ & $-0,001$ & $-0,011$ & $-0,025$ & $-0,003$ & $-0,015$ \\
\hline 21/06/99 & $-0,021$ & & $-0,016$ & 0,043 & 0032 & & 0,000 & $-0,011$ & 0,006 \\
\hline $16 / 08 / 99$ & $-0,014$ & $-0,007$ & $-0,015$ & $-0,015$ & $-0,011$ & $-0,016$ & 0,011 &, 018 & 0,011 \\
\hline $18 / 10 / 99$ & 0,000 & & 012 & 0,000 & 0,011 & 006 & $-0,002$ & 0,0 & 010 \\
\hline & & & & & & & & & \\
\hline $21 / 02 / 00$ & 0,018 & & & $-0,001$ & & & $-0,002$ & & $-0,018$ \\
\hline $17 / 04 / 00$ & 0,076 & & & $-0,038$ & $-0,040$ & $-0,030$ & $-0,009$ & $-0,010$ & 0,006 \\
\hline $19 / 06 / 00$ & 0,034 & 002 & 0,005 & $-0,002$ & $-0,025$ & $-0,020$ & $-0,002$ & $-0,030$ & $-0,027$ \\
\hline $21 / 08 / 00$ & $-0,005$ & 0,011 & 0,006 & $-0,016$ & $-0,006$ & $-0,011$ & $-0,024$ & $-0,009$ & $-0,013$ \\
\hline $16 / 10 / 00$ & 0,000 & & & & & & $-0,005$ & & 0,002 \\
\hline $18 / 12 / 00$ & $-0,011$ & & & & & & $-0,001$ & 007 & $-0,004$ \\
\hline $19 / 02 / 01$ & $-0,011$ & & & $-0,013$ & $-0,004$ & $-0,012$ & 0,020 & 0,034 & 0,024 \\
\hline $16 / 04 / 01$ & $-0,037$ & 0,005 & 0,013 & $-0,018$ & 0,010 & 0,011 & $-0,040$ & $-0,001$ & 0,006 \\
\hline $18 / 06 / 01$ & $-0,048$ & & & $-0,005$ & 0,028 & 0,026 & $-0,014$ & 0,031 & 0,035 \\
\hline $20 / 08 / 01$ & 0,027 & & & $-0,007$ & $-0,012$ & $-0,009$ & $-0,012$ & $-0,017$ & $-0,013$ \\
\hline $15 / 10 / 01$ & 0,079 & & & 0,028 & $-0,015$ & $-0,017$ & 0,068 & 0,014 & 0,003 \\
\hline $17 / 12 / 01$ & 0,008 & & 0,012 & $-0,008$ & $-0,006$ & $-0,007$ & 0,021 & 0,026 & 0,026 \\
\hline & & & & & & & & & \\
\hline D. Padrão & & 0,029 & 0,031 & & 0,018 & 0,023 & & 0,018 & 0,019 \\
\hline
\end{tabular}

Obs.: $\mathrm{R}_{\mathrm{j}, \mathrm{t}}$ é o retorno observado da ação j no período $\mathrm{t} ; \mathrm{RR}_{\mathrm{jt}}$ é o retorno extraordinário ou resíduo da ação $\mathrm{j}$ no período t em relação ao índice $\mathrm{R}_{\mathrm{m},{ }^{*}}$.

Para se determinar se os retornos extraordinários são significativamente diferentes de zero utilizou-se a estatística t de Student. A hipótese nula formulada é de que a média dos retornos extraordinários das ações nas datas dos eventos não é estatisticamente diferente da média dos retornos da população. 


\section{Tabela 3: Resultados do Teste t para os Retornos Extraordinários Diários das Ações para cada um dos Índices de Mercado (set./98 a dez./01)}

\begin{tabular}{|c|c|c|c|c|c|c|}
\hline \multicolumn{7}{|c|}{ População = 808 Eventos } \\
\hline & $\begin{array}{c}\mathbf{R R}_{\mathrm{TNLP}, \mathrm{t}} \\
\mathbf{R}_{\mathrm{IBOV}, \mathrm{t}}\end{array}$ & $\begin{array}{c}\mathbf{R}_{\text {TNLP4,t }} \\
\mathbf{R}_{\text {FGV100,t }}\end{array}$ & $\begin{array}{c}\mathbf{R R}_{\text {PETR } 4, \mathrm{t}} \\
\mathbf{R}_{\text {IBOV,t }}\end{array}$ & $\begin{array}{c}\text { RR }_{\text {PETR } 4, t} \\
\text { R }_{\text {FGV100,t }}\end{array}$ & $\begin{array}{c}\mathbf{R R}_{\text {TLPP4,t }} \\
\mathbf{R}_{\text {IBOV,t }}\end{array}$ & $\begin{array}{c}\mathbf{R R}_{\text {TLPP4,t }} \\
\mathbf{R}_{\text {FGV100,t }}\end{array}$ \\
\hline Média & $-0,00019$ & 0,00018 & 0,00034 & 0,00051 & 0,00001 & 0,00035 \\
\hline D. Padrão & 0,02411 & 0,02565 & 0,02071 & 0,02383 & 0,02235 & 0,02340 \\
\hline \multicolumn{7}{|c|}{ Amostra = 20 Eventos (datas de vencimento) } \\
\hline & $\begin{array}{c}\mathrm{RR}_{\mathrm{TNLP} 4, \mathrm{t}} \\
\mathrm{R}_{\mathrm{IBOV}, \mathrm{t}}\end{array}$ & $\begin{array}{c}\mathrm{RR}_{\mathrm{TNLP} 4, \mathrm{t}} \\
\mathrm{R}_{\mathrm{FGV} 100, \mathrm{t}}\end{array}$ & $\begin{array}{c}\mathrm{RR}_{\text {PETR } 4, \mathrm{t}} \\
\mathrm{R}_{\mathrm{IBOV}, \mathrm{t}}\end{array}$ & $\begin{array}{c}\mathrm{R}_{\text {PETR } 4, \mathrm{t}} \\
\mathrm{R}_{\mathrm{FGV} 100, \mathrm{t}}\end{array}$ & $\begin{array}{c}\mathrm{RR}_{\mathrm{TLPP} 4, \mathrm{t}} \\
\mathrm{R}_{\mathrm{IBOV}, \mathrm{t}}\end{array}$ & $\begin{array}{l}\mathrm{RR}_{\mathrm{TLPP} 4, \mathrm{t}} \\
\mathrm{R}_{\mathrm{FGV100,t}}\end{array}$ \\
\hline Média & 0,01407 & 0,01667 & $-0,00276$ & $-0,00091$ & 0,00184 & 0,00411 \\
\hline D. Padrão & 0,02935 & 0,03107 & 0,01846 & 0,02271 & 0,01768 & 0,01930 \\
\hline Teste $\mathbf{t}$ & 2,172 & 2,372 & $-0,750$ & $-0,280$ & 0,463 & 0,871 \\
\hline
\end{tabular}

Cabe lembrar que a hipótese implícita na interpretação dos resultados, segundo Ball e Brown (1968), é a de que a estatística de teste calculada supõe variância de retornos extraordinários constante fora dos períodos próximos à ocorrência dos eventos e independência de retornos extraordinários entre um intervalo de tempo e outro.

A 5\% de significância e com 19 graus de liberdade ( $\mathrm{n}=20)$, o valor crítico da estatística t é de 2,093. Para o caso de Telemar PN, utilizando-se os dois índices, não se pode afirmar que a hipótese nula é verdadeira, ou seja, que $\mathrm{RR}_{\mathrm{j} \mathrm{t}} \neq 0$; em outras palavras, existem comportamentos anormais no mercado da ação-objeto nas datas de vencimento dos contratos de opções. De forma contrária, para Petrobrás PN e Telesp PN é verdadeira a hipótese nula, ou seja, $\mathrm{RR}_{\mathrm{jt}}=0$.

Uma primeira conclusão é que, pelo menos para Telemar PN no período estudado, ocorre influência do mercado de opções sobre o mercado a vista, contestando a eficiência do mercado. O oposto acontece para Petrobrás PN e Telesp PN, atestando a eficiência do mercado. Segundo: existe a possibilidade de se obter retornos extraordinários, quer sejam eles positivos ou negativos, na época do vencimento dos contratos de opções. Uma terceira conclusão, mais prática, é que, embora os resultados pareçam a priori contraditórios, desde 1999 
as opções de Telemar PN começaram a liderar o mercado brasileiro desse tipo de derivativo, a tal ponto que suas opções sozinhas movimentam, em média, 30 vezes o volume financeiro de todas as outras opções sobre ações existentes. Em dias normais, suas opções movimentam até $50 \%$ do volume financeiro negociado no papel a vista, percentual que pode subir às vésperas do vencimento. Desta forma, pode-se, num primeiro momento, desprezar os resultados encontrados para Telesp PN e Petrobrás PN que, embora possuam boa liquidez, possuem opções com baixa negociabilidade. Isto tem como conseqüência uma baixa probabilidade de negócios simultâneos da ação e opção, o que pode tornar os resultados enviesados.

Adiante, apresentam-se, nas Tabelas 4, 5 e 6, os resultados obtidos, quando a mensuração dos efeitos do vencimento de opções é realizada sobre uma base semanal de retornos. Desta forma, pode-se avaliar que, existindo pressão do mercado de opções, alterações dos preços das ações do mercado a vista poderiam manifestar-se num período pré-evento, como a semana anterior ao vencimento das opções.

Tabela 4: Intercepto e Grau de Inclinação das Ações em Relação aos Índices de Mercado, com Retornos Semanais (set./98 a dez./01)

\begin{tabular}{llrrr} 
& & Intercepto & Inclinação & \multicolumn{1}{l}{$\mathbf{R}^{2}$} \\
\hline \multirow{2}{*}{ TNLP4 } & Ibovespa & 0,00377 & 1,22510 & 0,65675 \\
\cline { 2 - 5 } & FGV-100 & $-0,00109$ & 1,35198 & 0,53507 \\
\hline \multirow{2}{*}{ PETR4 } & Ibovespa & 0,00457 & 0,79414 & 0,41677 \\
\cline { 2 - 5 } & FGV-100 & 0,00166 & 0,85420 & 0,32258 \\
\hline \multirow{2}{*}{ TLPP4 } & Ibovespa & $-0,00271$ & 0,91513 & 0,48151 \\
\cline { 2 - 5 } & FGV-100 & $-0,00744$ & 0,91513 & 0,47499 \\
\hline
\end{tabular}


Tabela 5: Retornos Normais e Extraordinários Semanais das Ações para Cada um dos Índices de Mercado, na Semana Anterior ao Vencimento das Respectivas Opções, Usando o Modelo de Mercado (set./98 a dez./01)

\begin{tabular}{|c|c|c|c|c|c|c|c|c|c|}
\hline $\begin{array}{c}\text { Semana } \\
\text { Finda em }\end{array}$ & $\mathbf{R}_{\text {TNLP4,t }}$ & $\begin{array}{l}\mathbf{R R}_{\text {TNLP4, }} \\
\text { Ibovespa }\end{array}$ & $\begin{array}{l}\text { RR }_{\text {TNLP4,t }} \\
\text { FGV100 }\end{array}$ & $\mathbf{R}_{\text {PETR } 4, t}$ & \begin{tabular}{|l} 
RR $_{\text {PETR 4,t }}$ \\
Ibovespa
\end{tabular} & $\begin{array}{l}\text { RR } \\
\text { FGETR4, } \\
\text { FG100 }\end{array}$ & $\mathbf{R}_{\text {TLPP4, }}$ & $\mid \begin{array}{l}\mathbf{R}_{\text {TLPP4,t }} \\
\text { Ibovespa }\end{array}$ & $\begin{array}{l}\mathbf{R R}_{\text {TLPP4,t }} \\
\text { FGV100 }\end{array}$ \\
\hline $16 / 10 / 98$ & 0,091 & 0,054 & 0,063 & 0,121 & 0,095 & 0,101 & 0,095 & 0,072 & 0,083 \\
\hline $18 / 12 / 98$ & $-0,138$ & $-0,071$ & $-0,105$ & $-0,095$ & $-0,054$ & $-0,077$ & $-0,059$ & $-0,004$ & $-0,031$ \\
\hline 05/02/99 & $-0,034$ & $-0,077$ & $-0,018$ & 0,092 & 0,062 & 0,099 & $-0,028$ & $-0,055$ & $-0,010$ \\
\hline $16 / 04 / 99$ & $-0,045$ & $-0,060$ & $-0,092$ & 0,029 & 0,017 & $-0,003$ & $-0,007$ & $-0,012$ & $-0,032$ \\
\hline $18 / 06 / 99$ & 0,159 & 0,070 & 0,074 & 0,092 & 0,033 & 0,036 & 0,038 & $-0,023$ & $-0,014$ \\
\hline $13 / 08 / 99$ & $-0,024$ & $-0,045$ & $-0,043$ & $-0,010$ & $-0,026$ & $-0,024$ & 0,021 & 0,011 & 0,015 \\
\hline $15 / 10 / 99$ & 0,000 & 0,030 & 0,020 & $-0,051$ & $-0,034$ & $-0,041$ & $-0,004$ & 0,024 & 0,016 \\
\hline $17 / 12 / 99$ & 0,027 & 0,023 & 0,015 & $-0,007$ & $-0,012$ & $-0,018$ & $-0,046$ & $-0,044$ & $-0,048$ \\
\hline $18 / 02 / 00$ & 0,008 & 0,035 & 0,033 & 0,069 & 0,084 & 0,082 & $-0,051$ & $-0,025$ & $-0,027$ \\
\hline $14 / 04 / 00$ & $-0,251$ & $-0,065$ & $-0,089$ & $-0,101$ & 0,018 & $-0,001$ & $-0,095$ & 0,050 & 0,022 \\
\hline $16 / 06 / 00$ & $-0,007$ & $-0,017$ & $-0,001$ & 0,006 & $-0,003$ & 0,007 & $-0,041$ & $-0,043$ & $-0,030$ \\
\hline $18 / 08 / 00$ & 0,033 & 0,035 & 0,018 & 0,038 & 0,037 & 0,026 & 0,146 & 0,153 & 0,143 \\
\hline $13 / 10 / 00$ & $-0,081$ & $-0,041$ & $-0,029$ & 0,036 & 0,059 & 0,066 & $-0,075$ & $-0,040$ & $-0,034$ \\
\hline $15 / 12 / 00$ & 0,008 & 0,004 & 0,012 & 0,046 & 0,041 & 0,046 & 0,011 & 0,013 & 0,020 \\
\hline $16 / 02 / 01$ & $-0,035$ & 0,024 & 0,034 & 0,007 & 0,043 & 0,048 & $-0,061$ & $-0,011$ & $-0,008$ \\
\hline $13 / 04 / 01$ & 0,057 & 0,012 & 0,016 & $-0,026$ & $-0,057$ & $-0,054$ & 0,034 & 0,006 & 0,013 \\
\hline $15 / 06 / 01$ & $-0,045$ & $-0,019$ & $-0,025$ & $-0,017$ & $-0,002$ & $-0,007$ & $-0,050$ & $-0,025$ & $-0,030$ \\
\hline $17 / 08 / 01$ & $-0,064$ & 0,009 & $-0,013$ & $-0,015$ & 0,030 & 0,015 & 0,045 & 0,105 & 0,086 \\
\hline $12 / 10 / 01$ & 0,088 & 0,014 & 0,023 & 0,065 & 0,014 & 0,021 & 0,055 & 0,005 & 0,018 \\
\hline $14 / 12 / 01$ & $-0,032$ & $-0,005$ & $-0,019$ & $-0,043$ & $-0,028$ & $-0,038$ & 0,020 & 0,046 & 0,035 \\
\hline Média & & $-0,004$ & $-0,006$ & & 0,016 & 0,014 & & 0,010 & 0,009 \\
\hline D. Padrão & & 0,043 & 0,048 & & 0,043 & $\mathbf{0 , 0 5 0}$ & & $\mathbf{0 , 0 5 3}$ & 0,048 \\
\hline
\end{tabular}

Obs.: $R_{\mathrm{j}, \mathrm{t}}$ é o retorno semanal observado da ação $\mathrm{j}$ no período $\mathrm{t} ; \mathrm{RR}_{\mathrm{jt}}$ é o retorno extraordinário semanal da ação j no período t em relação ao índice $\mathrm{R}_{\mathrm{m}, \mathrm{t}^{*}}$. 


\section{Tabela 6: Resultados do Teste t para os Retornos Extraordinários Semanais das Ações para Cada um dos Índices de Mercado (set./98 a dez./01)}

\begin{tabular}{c|c|c|c|c|c|c}
\hline \multicolumn{7}{c}{ População = 171 Eventos } \\
\hline & $\begin{array}{c}\mathbf{R}_{\text {TNLP4,t }} \\
\mathbf{R}_{\text {IBOV,t }}\end{array}$ & $\begin{array}{c}\mathbf{R}_{\text {TNLP4,t }} \\
\mathbf{R}_{\text {FGV100,t }}\end{array}$ & $\begin{array}{c}\mathbf{R}_{\text {PETR4,t }} \\
\mathbf{R}_{\text {IBOV,t }}\end{array}$ & $\begin{array}{c}\mathbf{R}_{\text {PETR4,t }} \\
\mathbf{R}_{\text {FGV100,t }}\end{array}$ & $\begin{array}{c}\mathbf{R}_{\text {TLPP4,t }} \\
\mathbf{R}_{\text {IBOV,t }}\end{array}$ & $\begin{array}{c}\mathbf{R}_{\text {TLPP4,t }} \\
\mathbf{R}_{\text {FGV100,t }}\end{array}$ \\
\hline Média & $-0,00052$ & $-0,00074$ & 0,00186 & 0,00167 & 0,00119 & 0,00297 \\
\cline { 2 - 7 } D. Padrão & 0,04512 & 0,05231 & 0,04780 & 0,05180 & 0,04923 & 0,04949 \\
\hline
\end{tabular}

\begin{tabular}{|c|c|c|c|c|c|c|}
\hline \multicolumn{7}{|c|}{ Amostra $=20$ Eventos } \\
\hline & $\begin{array}{c}\mathbf{R R}_{\text {TNLP4,t }} \\
\mathbf{R}_{\text {IBOV }, \mathrm{t}}\end{array}$ & $\begin{array}{c}\mathbf{R R}_{\text {TNLP4,t }} \\
\mathbf{R}_{\text {FGV100,t }}\end{array}$ & $\begin{array}{c}\mathbf{R R}_{\text {PETR } 4, \mathrm{t}} \\
\mathbf{R}_{\text {IBOV }, \mathrm{t}}\end{array}$ & $\begin{array}{c}\text { RR }_{\text {PETR } 4, t} \\
\text { R }_{\text {FGV100,t }}\end{array}$ & $\begin{array}{c}\mathbf{R R}_{\text {TLPP4,t }} \\
\mathbf{R}_{\text {IBOV }, \mathrm{t}}\end{array}$ & $\begin{array}{l}\mathbf{R}_{\mathrm{TLPP} 4, \mathrm{t}} \\
\mathbf{R}_{\text {FGV100,t }}\end{array}$ \\
\hline Média & $-0,00444$ & $-0,00634$ & 0,01590 & 0,01431 & 0,01018 & 0,00939 \\
\hline D. Padrão & 0,04321 & 0,04826 & 0,04286 & 0,04981 & 0,05304 & 0,04821 \\
\hline Teste $t$ & $-0,406$ & $-0,519$ & 1,465 & 1,135 & 0,758 & 0,595 \\
\hline
\end{tabular}

A hipótese nula agora é de que a média semanal dos resíduos dos retornos das ações nas vésperas das datas dos eventos não é estatisticamente diferente dos retornos semanais do período analisado, compreendendo 171 semanas.

A 5\% de significância e com 19 graus de liberdade $(n=20)$, em todos os casos pode-se afirmar que a hipótese nula é verdadeira, ou seja, que $\mathrm{RR}_{\mathrm{jt}}=0$. Esses resultados indicam que não se observa qualquer pressão ou influência do mercado de opções sobre o mercado de ações a vista na semana que precede o vencimento do mercado de opções, comportamento este que condiz com o de um mercado eficiente. Aqui convém lembrar que se encontrou forte indício de influência nas datas de vencimento, quando foram utilizados retornos diários das ações objeto; no entanto não se pode deixar de observar, para a série mais líquida da Telemar PN, que houve tendência de retornos negativos na semana anterior ao vencimento de sua opção, resultados semelhantes aos encontrados nos trabalhos de Klemkosky (1978) e Officer e Trennepohl (1981) nos EUA e Pope e Yadav (1992) no Reino Unido.

\section{Causalidade entre os Mercados de Opções e a Vista}

Os preços, a quantidade de negócios e o volume financeiro transacionado no mercado de opções e no mercado a vista estão de alguma forma correlacionados. Primeiramente, devido à utilização de estratégias com combinações de ações e opções, seja por hedge ou alavancagem; segundo, devido ao fluxo de informações relevantes que chegam ao mercado, conforme vimos na revisão bibliográfica deste trabalho. 
É de se esperar que o nível de atividades esteja relacionado, devendo ser constatada certa correlação entre variáveis como a quantidade de negócios efetuados em cada mercado e, também, o volume transacionado em cada mercado. Sanvicente (1996) estudou este correlacionamento por meio do número de negócios efetuados nos dois mercados. No presente trabalho, optou-se por utilizar o volume negociado como proxy para analisar a relação entre o mercado a vista e o de opções. Essa é a sugestão de Copeland (1976) e que foi seguida na maioria dos trabalhos sobre o assunto, como Morse (1980), Manaster e Rendleman (1982) e Anthony (1988). Além do mais, uma ação ou uma opção não são bens quaisquer: as quantidades são limitadas e quem forma seu preço são compradores e vendedores em função de estimativas de seu valor intrínseco. Assim, o que altera o ponto de equilíbrio preço-quantidade entre demanda e oferta é o volume negociado do ativo. Baixa quantidade de negócios pode implicar em alto volume financeiro negociado (como a compra e venda feita por instituições para montagens de box para suas carteiras, por exemplo), bem como alto número de negócios pode implicar em baixo volume negociado (como a compra e venda em dias normais por pessoas físicas). Assim, o melhor parâmetro para análise é o volume negociado de um ativo, e não o número de negócios realizados.

A atividade no mercado de opções pode antecipar-se às variações de atividade no mercado a vista correspondente, porque os possuidores de informação relevante tendem, por motivos de custos transacionais e alavancagem, a preferir aproveitar essas informações no mercado de opções, conforme Black (1975).

Como afirmado anteriormente, opções são instrumentos derivativos de ações, índices e outros contratos. Para o presente caso, é de se esperar que o mercado a vista cause - no sentido de Granger (1969) - o mercado de opções, mas embora uma análise desse tipo envolva dependência de uma variável em relação a outra, isso não implica necessariamente causalidade. A metodologia de Granger supõe que a variável $Y$ causa (no sentido de Granger) $X$ se, ao se utilizar um teste $F$, for possível rejeitar a hipótese nula de que os valores passados (lagged) de Y não explicam a parte da variância de X que não é explicada pelos valores passados do próprio $\mathrm{X}$.

Supondo que duas variáveis se afetam reciprocamente com defasagens (distribuídas), é possível dizer então que a primeira "causa" a outra $(\mathrm{X} \rightarrow \mathrm{Y})$, ou o contrário $(\mathrm{Y} \rightarrow \mathrm{X})$, ou ainda que existe uma realimentação entre essas duas variáveis $(\mathrm{X} \rightarrow \mathrm{Y} \rightarrow \mathrm{X})$.

Nesta parte do trabalho, o objetivo é verificar se é possível detectar a direção de causalidade, quando houver temporalmente uma relação de liderança e defasagem entre duas variáveis quaisquer. 
Procura-se examinar a causalidade entre os mercados de opções e a vista, utilizando o método proposto por Granger (1969), que supõe que as informações relevantes para previsão das variáveis estão contidas exclusivamente nos dados das séries temporais destas mesmas variáveis. O teste envolve a estimativa das seguintes regressões:

$$
\begin{aligned}
& Y_{t}=\sum_{i=1}^{n} \alpha_{i} X_{t-i}+\sum_{j=1}^{n} \beta_{j} Y_{t-j}+u_{t} \\
& X_{t}=\sum_{i=1}^{m} \lambda_{i} X_{t-i}+\sum_{j=1}^{m} \delta_{j} Y_{t-j}+v_{t}
\end{aligned}
$$

onde $\mathrm{Y}$ e $\mathrm{X}$ são as variáveis a serem testadas; $\alpha, \beta, \delta$ e $\lambda$ são os coeficientes das regressões a serem estimados; e u e v são as perturbações supostas não correlacionadas.

A significância da hipótese nula de causalidade pode ser verificada por meio da utilização de um teste F, conforme Gujarati (1995). Assim, com o uso do software de econometria Eviews, torna-se possível a aplicação dos testes de causalidade de Granger para as variáveis selecionadas, além de se verificar, por meio de testes de raiz unitária, a sua estacionariedade.

Para se testar a causalidade entre os dois mercados, foram utilizados os três últimos exercícios de opções de 2001 (20 de agosto, 15 de outubro e 17 de dezembro) de Telemar PN, em função de sua liquidez, verificando a interação entre as séries de retorno diárias das opções mais negociadas no início do período de trade de cada vencimento, ou seja, da série composta pelas opções in-themoney, at-the-money e out-of-the-money, a partir do valor da ação-objeto do mercado a vista no início deste período. Os dados utilizados das séries de retornos de opções foram coletados no banco de dados da Hedging-Griffo Corretora de Valores S.A. e os dados do papel a vista, no banco de dados da Economática, respeitando as considerações feitas no item Análise Empírica.

Conforme se observa no início desta seção, optou-se por avaliar a relação de causalidade de Granger entre o volume negociado entre os mercados e entre os preços de fechamento dos papéis nos dois mercados. Foram utilizados os dados, quando possível, dos negócios com opções anteriores ao vencimento anterior, ou seja, sempre que possível, as séries utilizadas para o vencimento presente iniciaram antes mesmo do vencimento passado.

Está-se aqui, considerando quatro possibilidades, ou em outros termos, estabelecendo quatro hipóteses nulas: 
a) o volume negociado no mercado de opções não causa o volume no mercado a vista;

b) o volume negociado no mercado a vista não causa o volume no mercado de opções;

c) retorno do mercado de opções não causa o retorno do mercado a vista; e

d) retorno do mercado a vista não causa o retorno do mercado de opções.

Os testes foram efetuados, considerando-se até 5 pregões de defasagem, desconsiderando-se os pregões onde não houve negócios com opções das séries analisadas. Os resultados são apresentados na Tabela 7, a seguir.

\section{Tabela 7: Testes de Causalidade de Granger entre o Mercado a Vista e o Mercado de Opções para as Variáveis Volume de Negócios Diários e Preço de Fechamento Diário}

\begin{tabular}{|c|c|c|c|c|}
\hline $\begin{array}{c}\text { Série } \\
\text { mês-preço }\end{array}$ & $\begin{array}{l}\text { Hipótese Nula (a) } \\
\text { Est.F [P-valor] }\end{array}$ & $\begin{array}{l}\text { Hipótese Nula (b) } \\
\text { Est.F [P-valor] }\end{array}$ & $\begin{array}{l}\text { Hipótese Nula (c) } \\
\text { Est.F [P-valor] }\end{array}$ & $\begin{array}{c}\text { Hipótese Nula (d) } \\
\text { Est.F [P-valor] }\end{array}$ \\
\hline dez-24 & $0, .6631[0,6796]$ & $0,9928[0,4433]$ & $65,749[0,0000] * *$ & $67,537[0,0000] * *$ \\
\hline dez-26 & $2,1904[0,0652]$ & $1,1255[0,3662]$ & $59,71[0,0000] * *$ & $61,016[0,0000] * *$ \\
\hline dez-28 & $2,1102[0,0761]$ & $1,3229[0,2723]$ & $45,45[0,0000] * *$ & $42,745[0,0000] * *$ \\
\hline out-28 & $1,5859[0,1869]$ & $1,3906[0,2518]$ & $5,6311[0,0006] * *$ & $5,6366[0,0006] * *$ \\
\hline out-30 & $0,4121[0,8644]$ & $1,9537[0,1081]$ & $1,8561[0,1255]$ & $1,5554[0,1985]$ \\
\hline out-32 & $1,1067[0,3809]$ & $0,9888[0,4498]$ & $6,6289[0,0001] * *$ & $8,3293[0,0000] * *$ \\
\hline ago-34 & $1,2236[0,3229]$ & $2,0195[0,0952]$ & $5,7242[0,0005] * *$ & $6,6787[0,0002] * *$ \\
\hline ago-36 & $2,1109[0,0745]$ & $1,7229[0,1422]$ & $5,8697[0,0002] * *$ & $5,9608[0,0002] * *$ \\
\hline ago-38 & $1,7185[0,1467]$ & $1,9654[0,0983]$ & $8,8121[0,0000] * *$ & $10,54[0,0000] * *$ \\
\hline
\end{tabular}

(**) Hipótese Nula rejeitada a $1 \%$ de significância.

Com os dados da Tabela 5 pode-se concluir que existem evidências de causalidade bilateral ou realimentação dos retornos (hipóteses $c$ e $d$ ) entre os mercados de ações e de opções, já que na maioria dos casos (na realidade, afora apenas a série J30), a estatística F é significante a $1 \%$.

Em nenhum dos casos considerados há evidência de que nem o volume de títulos negociado no mercado de opções cause o volume de títulos no mercado a vista (hipótese $a$ ), nem o contrário (hipótese $b$ ), embora um aumento no 
número de defasagens provoque redução dos p-valores da hipótese (a) maior do que na hipótese (b), o que implica uma tendência maior de que o volume de títulos negociados no mercado de opções cause, no sentido de Granger (1969), a mesma variável do mercado a vista.

Não havendo causalidade significativa, com até 5 pregões, não existe evidência de que a atividade em um mercado cause atividade em outro, sendo isso um sinal de ilimitada influência informacional do mercado como um todo, ou seja, que nenhum mercado lidera ou influencia o outro e ambos os mercados reagem de maneira simultânea ao aparecimento de novas informações ou fatos relevantes. Sanvicente (1996) constatou que as informações chegavam com uma antecedência de dois dias ou mais no mercado de opções em detrimento do mercado a vista, no entanto, como discutido anteriormente, o autor usou como variável proxy o número de negócios, em vez do volume negociado.

Até este ponto foram utilizados sempre os preços de fechamento das ações e opções para o cálculo dos retornos. É importante verificar se os preços das opções e das ações estão sendo observados exatamente nos mesmos instantes, não sendo adequado testar as relações de causalidade e influência de um mercado sobre o outro com os preços de abertura ou de fechamento (maioria dos trabalhos empíricos). Isso se justifica pelo fato de que, na maioria das bolsas do mundo, existem leilões de abertura e fechamento dos negócios, e os tempos de observação são diferentes. O fechamento (leilão) de uma ação no mercado a vista pode ser mais cedo do que o de uma opção de compra dela, o que ocasionaria uma diferença de preços que só seria corrigida no pregão seguinte. Assim, ficam menos imunes ao viés de escolha, os preços máximos e mínimos das ações e opções.

Desta maneira, em nível exploratório, decidiu-se, adicionalmente à utilização dos retornos calculados por meio das cotações de fechamento, testar as nove séries de retornos, utilizando as cotações máximas diárias, tanto dos papéis a vista quanto das opções, procurando encontrar evidências que justifiquem a sua utilização. Os resultados estão na Tabela 8. 


\section{Tabela 8: Testes de Causalidade de Granger entre o Mercado a Vista e o Mercado de Opções para a Variável Preço Máximo Diário}

\begin{tabular}{c|c|c}
\hline \multirow{2}{*}{$\begin{array}{c}\text { Série } \\
\text { mês-preço }\end{array}$} & $\begin{array}{c}\text { Hipótese Nula (c) } \\
\text { Est.F [P-valor] }\end{array}$ & $\begin{array}{c}\text { Hipótese Nula (d) } \\
\text { Est.F [P-valor] }\end{array}$ \\
\hline dez-24 & $67,8783[0,0000] * *$ & $69,4230[0,0000] * *$ \\
dez-26 & $57,7214[0,0000] * *$ & $65,8762[0,0000] * *$ \\
dez-28 & $38,6092[0,0000] * *$ & $35,5591[0,0000] * *$ \\
out-28 & $6,5333[0,0003] * *$ & $6,1234[0,0002] * *$ \\
\cline { 2 - 3 } out-30 & $1,9546[0,0854]$ & $1,7612[0,1565]$ \\
\cline { 2 - 3 } out-32 & $6,0253[0,0002] * *$ & $7,798[0,0002] * *$ \\
\cline { 2 - 3 } $\begin{array}{c}\text { ago-34 } \\
\text { ago-36 }\end{array}$ & $6,5702[0,0002] * *$ & $8,2863[0,0000] * *$ \\
\cline { 2 - 3 } \begin{tabular}{c} 
ago-38 \\
\cline { 2 - 3 }
\end{tabular} & $5,1617[0,0006] * *$ & $6,3374[0,0001] * *$ \\
\cline { 2 - 4 } & $5,9084[0,0003] * *$ & $6,3755[0,0001] * *$ \\
\hline
\end{tabular}

(**) Hipótese Nula rejeitada a $1 \%$ de significância.

Nos resultados encontrados, observa-se, para cada uma das três séries analisadas, que quanto mais in-the-money é a série, mais importante se torna a utilização dos retornos calculados sobre os preços máximos dos dois mercados para efeitos de cálculo de regressão. Percebe-se, sem a diminuição substancial do p-valor, um aumento na estatística F no sentido das opções in-the-money, que mede a significância global das regressões, o que implica diretamente em aumento no $R^{2}$ das regressões estimadas.

Esta parte exploratória do estudo justifica-se nos resultados de Blume e Stambaugh (1983) sobre o viés causado pelo cálculo de retornos diários, usandose preços de fechamento e também no trabalho recente de Fiess e MacDonald (2002) sobre o conteúdo informacional adicional, proporcionado por cotações de preços máximos e mínimos para o uso em previsões de séries temporais e em testes de causalidade de Granger.

\section{Conclusões e Recomendações}

Os testes efetuados na seção Influência do Vencimento do Mercado de Opções sobre o Mercado a Vista, com os dados diários indicam que, pelo menos para Telemar PN no período estudado, ocorreu influência do mercado de opções sobre o mercado a vista, contrariando a eficiência do mercado; e que se poderia, pelo 
menos em teoria, obter retornos extraordinários na época do vencimento dos contratos de opções. Este resultado confirma o encontrado por Sanvicente e Monteiro (2002), utilizando dados intradiários.

Com os dados semanais, em todos os casos pode-se afirmar que a hipótese nula é verdadeira, ou seja, que $\mathrm{RR}_{\mathrm{jt}}=0$, o que indica que não se observou nenhuma pressão ou influência do mercado de opções sobre o mercado de ações a vista na semana que precede o vencimento do mercado de opções, resultado semelhante aos encontrados por Sanvicente e Kerr (1989), Sanvicente (1996) e Körbes e Costa Jr. (2001), para o Brasil; no entanto, para a série mais líquida (Telemar $\mathrm{PN}$ ), observaram-se retornos negativos (não significativos) na semana anterior ao vencimento, resultado semelhante ao encontrado no mercado americano e britânico.

Os testes efetuados na seção Causalidade entre os Mercados de Opções e a Vista indicam a existência de causalidade bilateral dos retornos entre os mercados de ações e de opções, já que na maioria dos casos a estatística $F$ foi significante a $1 \%$.

Em nenhum dos casos considerados houve evidência de que nem o volume de títulos negociado no mercado de opções cause o volume de títulos no mercado a vista, nem o contrário, sendo isso um sinal de ilimitada influência informacional do mercado como um todo, ou seja: nenhum mercado lidera ou influencia o outro e ambos os mercados reagem de maneira simultânea ao aparecimento de novas informações.

Uma análise mais apurada sobre a causalidade levanta o problema dos resultados obtidos. Por causa das defasagens envolvidas, os modelos distribuídos e/ou autorregressivos levantam a questão da causalidade entre as variáveis econômicas, onde é necessário grande cautela com a metodologia de Granger (1969), pois ela é muito sensível ao tamanho da defasagem usada no modelo. Uma proposta futura é utilizar o teste de causalidade de Sims (1972), que explora o fato de que o futuro não pode causar o presente, com as regressões incluindo os valores defasados atuais e futuros.

Por fim, por meio da comparação entre os resultados encontrados para nove séries de opções com retornos calculados sobre os valores máximos de pregão, observou-se que quanto mais in-the-money era a série, mais importante se tornou a utilização dos retornos calculados sobre os preços máximos para fins da análise de causalidade proposta.

Artigo recebido em 31.01.2004. Aprovado em 22.04.2004. 


\section{NOTA}

${ }^{1}$ Existe também um volume significativo de estudos que têm como foco o impacto da introdução de contratos derivativos nas características de retorno e risco dos ativos subjacentes.

\section{ReFERÊNCIAS BibliográficAS}

Anthony, J. (1988, September).

The interrelation of stock and options market trading-volume data. Journal of Finance, 43(4), 949-964.

Ball, R., \&

Brown, P. (1968, Autumn).

An empirical evaluation of accounting income numbers. Journal of Accounting Research, 6(2), 159178.

Black, F., \&

Scholes, M. (1973, May/June).

The pricing of options and corporate liabilities. Journal of Political Economy, 81(3), 637-654.

Black, F. (1975, July/August).

Fact and Fantasy in the use of options. Financial Analysts Journal, 31(4), 36-72.

Bhattacharya, M. (1987, March).

Price changes of related securities: the case of call options and stocks. Journal of Financial and Quantitative Analysis, 22(1), 1-15.

Blume, M.E., \&

Stambaugh, R.F. (1983, October).

Biases in computed returns: an application to the size effect. Journal of Financial Economics, 12(3), 387404.
Boyle, P. P.,

Byoun, S., \&

Park, H.Y. (1999).

Temporal price relation between stock and option markets and a bias of implied volatility in option prices. [working paper]. University of Illinois at Urbana-Champaign (OFOR 99-07).

Brito, N. R. O.de, \&

Sosin, H. B. (1984).

$\mathrm{O}$ efeito de vencimentos futuros sobre a formação de preços no mercado à vista de ações. In: N. R. O. Brito, de,(Ed.). Mercados futuros: sua relevância e experiência. Rio de Janeiro: Ao Livro Técnico.

Chan, K.,

Chung, P., \&

Johnson, H. (1993, December).

Why option prices lag stock prices: a trading based explanation. Journal of Finance, 48(5), 1957-1967.

Chen, K. C., \&

Wu, L. (2001, Spring).

Introduction and expiration effects of derivative equity warrants in Hong Kong. International Review of Financial Analysis, 10(1), 37-52. 
Copeland, T. E. (1976, September).

A model of asset trading under the assumption of sequential information arrival. Journal of Finance, 31(4), 1149-1168.

Fama, E. F.,

Fisher, L.,

Jensen, M. C., \&

Roll, R. (1969, February).

The adjustment of stock prices to new information. International Economic Review, 10(1), 1-21.

Felixson, K. (2002).

The expiration day effect of index options and index futures on the underlying shares. [working paper] Swedish School of Economics and Business Administration (473).

Fiess, N. M., \&

MacDonald, R. (2002, May).

Towards the fundamentals of technical analysis: analysing the information contents of high, low and close prices. Economic Modelling, 19(3), 353-374.

Finnerty, J., \&

Park, H. (1987, March/April).

Stock index futures: Does the tail wag the dog? Financial Analyst Journal, 43(2), 57-61.

Granger, C. W. J. (1969, August).

Investigating causal relations by econometric models and crossspectral methods. Econometrica, 37(3), 424-38.

Gujarati, D. N. (1995).

Basic Econometric (3rd ed.). New York: McGraw-Hill.
Kawaller, I.,

Koch, P., \&

Koch, T. (1987, December).

The temporal price relation between S\&P500 futures and S\&P500 index. Journal of Finance, 42(5), 1309-1329.

Kleidon, A., \&

Whaley, R. (1992, July).

One market? Stocks, futures and options during October 1987. Journal of Finance, 47(3), 851-877.

Klemkosky, R. C. (1978, September).

The impact of option expiration on stock prices. Journal of Financial and Quantitative Analysis, 12(3), 507-517.

Körbes, P. J., \&

Costa, N. C. A., Jr., da (2001).

Existe influência do vencimento das opções sobre o mercado à vista? In: E. F. Lemgruber, A. L. C. Silva, R. P. C. Leal, N. C. A. Costa, Jr., da (Orgs.). Gestão de risco e derivativos: aplicações no Brasil. São Paulo: Atlas.

Manaster, S., \&

Rendleman, R. J. (1982, September).

Option prices as predictors of equilibrium stock prices. Journal of Finance, 37(4), 10431057.

Morse, D. (1980, December).

Asymmetrical information in securities markets and trading volume. Journal of Financial and Quantitative Analysis, 15(4), 11291148

Officer, D., \&

Trennepohl, G. L. (1981, Summer).

Price behavior of corporate equities near option expiration dates. Financial Management, 10(2), 75-80. 
Ostdiek, B.,

Fleming, J., \&

Whaley, R. (1993).

The integration of stock, futures and option market returns [working paper]. Duke University.

Pope, P., \&

Yadav, P. (1992, April).

The impact of option expiration on underlying stocks: the UK evidence. Journal of Business Finance and Accounting, 19(3), 329-344.

Sanvicente, A. Z. (1996).

Interação do mercado de opções com o mercado a vista de ações [working paper]. Ibmec.

Sanvicente, A. Z. (2003).

Derivativos. São Paulo: PubliFolha.

Sanvicente, A. Z., \&

Kerr, R. B. (1989, janeiro/março).

O mercado de ações e o vencimento de opções de compra. Revista de Administração (USP), 24(1), 23-32.
Sanvicente, A. Z., \&

Monteiro, R. (2002).

A guerra entre comprados e vendidos no mercado de opções de compra da Bolsa de Valores de São Paulo. Anais do Encontro Brasileiro de Finanças, Rio de Janeiro, 2, p. 12.

Sims, C. A. (1972, September).

Money, income and causality. American Economic Review, 62(4), 540-552.

Stephan, J., \&

Whaley, R. (1990, March).

Intra-day price changes and trading volume relations in the stock and stock option markets. Journal of Finance, 45(1), 191-220.

Stoll, H. R., \&

Whaley, R. (1987, March/April).

Program trading and expiration-day effects. Financial Analysts Journal, 43(2), 16-28.

Stoll, H. R., \&

Whaley, R. (1991, January-February).

Expiration-day effects: what has changed? Financial Analysts Journal, 47(1) 58-72. 